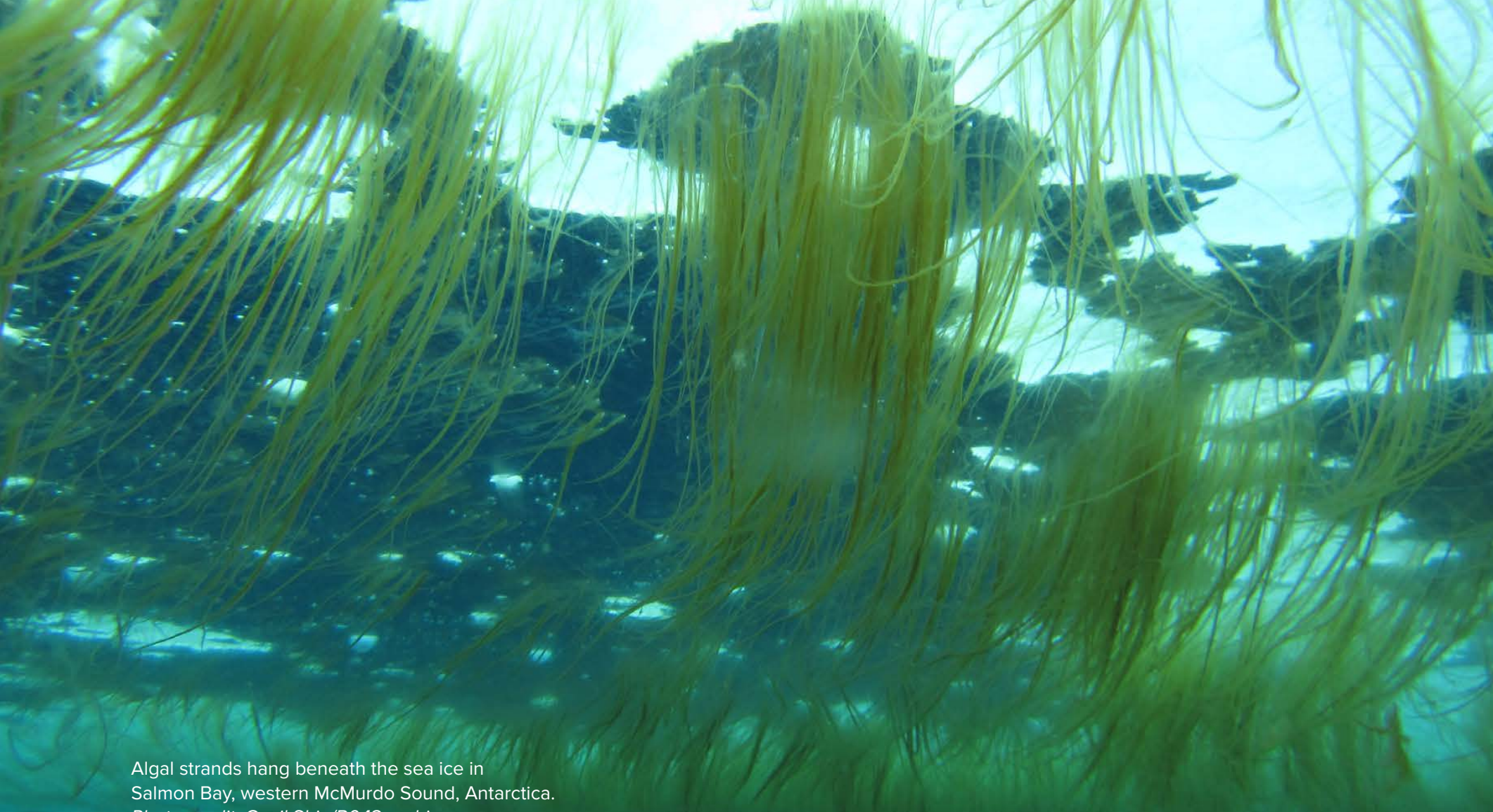

Salmon Bay, western McMurdo Sound, Antarctica.

Photo credit: Cecil Shin/B043 archive

\title{
SIDEBAR. Diatoms as Sea Ice Proxies
}

By Amy Leventer

Diatoms can live almost anywhere, but one of the most unusual places is within sea ice. These single-celled algae concentrate in newly forming sea ice and tinge the slushy surface a golden brown. They live in small channels between ice crystals and also on algal strands that hang from the underside of the ice. When the spring melt comes, diatoms in the sea ice serve as the seed population for ice-marginal blooms. The use of polar marine diatoms as a proxy for past sea ice relies upon their abundance, diversity, and preservation. In sediments, the presence of obligate sea ice diatoms, those species whose habitat is limited to within the sea ice, is reliable evidence of overlying sea ice. However, these species tend to be lightly silicified and underrepresented in marine sediments. Hence, while their presence is diagnostic, their absence is more difficult to interpret. Consequently, most sea ice reconstructions rely on species common in the marginal ice zone, seeded from melting sea ice into the adjacent open water. Many of these taxa have robust frustules that are well preserved at the seafloor.

Diatom-based sea ice reconstructions date to the early 1980 s, with increasingly quantitative work beginning in the mid-1990s and continuing today. Reconstructing past Southern Ocean sea ice presence is most readily accomplished in sediments with extant species, ground truthed by modern observations. Thus, it is more difficult to use diatom-based sea ice proxies for time periods that harbored extinct species because the paleoenvironmental affiliation of these species is uncertain. Several approaches, in combination, are possible to circumvent this issue. First, diagnostic evolutionary lineages can be traced (e.g., at present, many small pennate taxa within the genus Fragilariopsis are associated with sea ice)-but can we assume their ancestors had the same preferences? Second, specific morphologic characteristics (e.g., the development of resting spores or more heavily silicified winter stages) may have evolved following the initial or persistent occurrence of annual sea ice.

The use of diatom proxies for paleo sea ice extent also has its shortcomings, including biases associated with preferential grazing, water column dissolution, horizontal displacement by surface and bottom currents, and degradation within the sediments. Thus, while diatom assemblages reveal important clues to past sea ice presence, the imperfect sedimentary record of diatom assemblages has motivated development of new complementary biomolecular sea ice proxies.

\section{REFERENCES}

Leventer, A. 1998. The fate of sea ice diatoms and their use as paleoenvironmental indicators. Pp. 121-137 in Antarctic Sea Ice: Biological Processes, Interactions and Variability. M.P. Lizotte and K.R. Arrigo, eds, Antarctic Research Series, vol. 73, American Geophysical Union, Washington, DC

Armand, L., and A. Leventer. 2010. Palaeo sea ice distribution and reconstruction derived from the geological record. Pp. 469-530 in Sea Ice: An Introduction to its Physics, Biology, Chemistry, and Geology. D.N. Thomas and G.S. Dieckmann, eds, Blackwell Science.

Gersonde, R., and U. Zielinski. 2000. The reconstruction of late Quaternary Antarctic sea-ice distribution-The use of diatoms as a proxy for sea-ice. Palaeogeography, Palaeoclimatology, Palaeoecology 162 (3-4):263-286, https://doi.org/10.1016/S0031-0182(00)00131-0.

\section{AUTHOR}

Amy Leventer (aleventer@colgate.edu) is Professor, Department of Geology, Colgate University, Hamilton, NY, USA. 